\section{ARTICLE}

Sarah Levy, Hazel Mitchell, Guled Guled and Jessica Coleman

Office for National Statistics

\title{
Total reward: \\ pay and pension contributions in the private and public sectors
}

\section{Introduction}

$\mathrm{n}$ recent months, some commentators have argued that, taking account of pensions as well as pay, public sector employees in the UK receive better remuneration than their counterparts in the private sector. This article analyses the evidence from the Annual Survey of Hours and Earnings (ASHE) of the Office for National Statistics (ONS) ${ }^{1}$, and finds that the answers are more complex than such claims suggest.

The analysis compares the gross pay, employer pension contributions and 'total reward' of full-time employees working in the public and private sectors. It does not include the self-employed, who are not covered by the ASHE dataset.

The concept of total reward means different things to different people. The broadest definitions add together gross pay and benefits, which range from additional money benefits to benefits in kind and even quality of life in the workplace. This may also be called the 'overall reward package'. In this article, however, a narrow definition of total reward is used, consisting of gross pay plus employer pension contributions.

Total reward can also be seen as the sum of current and deferred earnings, or earnings received now and earnings which accumulate to be paid as a pension when the employee retires. From this perspective, deferred earnings include both employer pension contributions (on top of gross pay) and employee pension contributions, which are deducted from gross pay.

When asked how much they earn, most people quote their gross pay rather than total reward. However, in many cases the employer pension contribution is a significant part of an employee's remuneration. It also represents a major cost to public and private sector employers. For these reasons, the Independent Public Service Pensions Commission chaired by John Hutton, which began work in June $2010^{2}$, is interested in the question of total reward.

\section{Strengths and weaknesses of the data}

This article presents analysis based on the latest available ASHE, which relates to the employee's pay period (for example, a week or a month) that included 22 April 2009. The ASHE dataset is based on a 1 per cent sample of employee jobs taken from the PAYE records of HM Revenue \& Customs. ASHE is a large-scale survey, and is regarded as the best source for estimating average earnings in the UK. However, low-paid workers earning below the PAYE threshold may be underrepresented.

The standard presentation of average earnings estimates in ASHE is in the form of gross pay, which is pay before tax, National Insurance or other deductions, and excluding payments in kind. This article goes beyond this to analyse gross pay plus employer pension contributions. Although ASHE is considered the best source for such analysis, the following limitation of the dataset should be borne in mind.

The data for employer pension 
Table 1

Gross pay and total reward: summary statistics, ${ }^{1,2}$ April 2009

United Kingdom

\begin{tabular}{|c|c|c|c|c|c|c|c|c|}
\hline & & & & . \\
\hline & \multicolumn{4}{|c|}{ Gross pay } & \multicolumn{4}{|c|}{ Total reward } \\
\hline & \multicolumn{3}{|c|}{ 1st } & \multirow{2}{*}{$\begin{array}{r}\text { 3rd } \\
\text { quartile }\end{array}$} & \multicolumn{3}{|c|}{ 1st } & \multirow{2}{*}{$\begin{array}{r}3 \mathrm{rd} \\
\text { quartile }\end{array}$} \\
\hline & Mean & quartile & Median & & Mean & quartile & Median & \\
\hline Total & 587 & 348 & 489 & 693 & 636 & 364 & 523 & 761 \\
\hline Men & 643 & 379 & 531 & 753 & 695 & 394 & 565 & 825 \\
\hline Women & 501 & 313 & 426 & 613 & 546 & 329 & 462 & 674 \\
\hline \multicolumn{9}{|c|}{ Private sector } \\
\hline Total & 581 & 330 & 465 & 677 & 614 & 335 & 479 & 718 \\
\hline Men & 633 & 364 & 509 & 735 & 671 & 371 & 528 & 779 \\
\hline Women & 466 & 282 & 373 & 543 & 488 & 287 & 383 & 573 \\
\hline \multicolumn{9}{|c|}{ Public sector } \\
\hline Total & 605 & 393 & 539 & 722 & 692 & 444 & 615 & 829 \\
\hline Men & 679 & 433 & 591 & 791 & 780 & 492 & 680 & 917 \\
\hline Women & 545 & 363 & 496 & 663 & 621 & 411 & 564 & 756 \\
\hline
\end{tabular}

Notes:

Source: $A S H E$

1 Results are for full-time employees on adult rates of pay whose earnings were not affected by absence.

2 Total reward is defined as gross pay plus employer pension contributions.

contributions includes lump sum payments, which are typically paid at the end of a financial year and may cover a period that is longer than the pay period in question. It is not always possible to distinguish such payments from regular pension contributions, so in a few cases at the top end of the earnings distribution, employer pension contributions (and therefore total reward) may be inflated. In the following analysis, this is likely to have an impact on the mean (average) and on the highest (10th) decile point in the distribution (decile points divide the distribution into 10 equal parts so that each part contains 10 per cent of the distribution). For this reason, the analysis focuses on the median (that is, the midpoint of the distribution), as the preferred measure of the average, and on the 9th rather than the 10th decile point.

Another limitation of ASHE and other sources of data on employer pension contributions is that they may underestimate the true cost to the employer of pension contributions. In recent months, some commentators have argued that this is particularly so for public sector schemes. However, it also applies to defined benefit (salary-based) schemes in the private sector which may have to make up deficits in their pension funds with 'special contributions'. Special contributions from employers are not reported in the data for individual employees which is analysed in this article.

It should also be noted that an analysis of total reward (gross pay plus employer pension contributions) does not constitute a complete analysis of every aspect of pension provision in the public and private sectors. This is not possible using the ASHE dataset, nor is there a single source of data capable of doing this - although the ONS publication Pension Trends ${ }^{3}$ brings together several sources to analyse various aspects of pension provision.

Some readers may be interested in a time series for the information presented in this article. It was decided not to present a time series for two reasons. First, ASHE has only collected information on employer pension contributions since 2005 so, at present, a long time series is unavailable. Second, between 2008 and 2009 Lloyds Banking Group, the Royal Bank of Scotland Group and HBOS PLC were reclassified from the private sector to the public sector, so between 2008 and 2009 there is a break in any time series comparing the public and private sectors.

Finally, it is worth bearing in mind that in April 2009, the UK economy was in recession. This depressed earnings growth in the private sector ${ }^{4}$. Therefore comparisons between pay in the public and private sectors in April 2009 may be more than usually favourable to the public sector.

\section{The analytical approach}

The evidence presented in the remainder of this article addresses the question, 'Is there a difference between public and private sector employees in terms of pay and pension contributions?'

The first part of the analysis compares the gross pay and total reward of all fulltime employees in the public and private sectors in April 2009. The findings from this stage of the analysis suggest that public sector employees are better remunerated than their counterparts in the private sector. However, this is because only 43 per cent of full-time employees in the private sector belong to employer pension schemes (57 per cent have zero pension contributions), while in the public sector 90 per cent are members (10 per cent have zero pension contributions) $)^{5}$.

In the second part of the analysis, total reward in the two sectors is compared on a like-for-like basis in terms of pension scheme participation, looking at full-time employees with pension contributions. On this basis (excluding those with zero pension contributions), the result is different: total reward is higher in the private sector than in the public sector.

\section{Results - all employees}

Table 1 shows the results of analysing gross pay and total reward for all full-time employees on adult rates of pay whose earnings were not affected by absence in the pay period in question. In April 2009, median total reward was $£ 523$ per week, compared with median gross pay of $£ 489$ per week. Comparing the public and private sectors, the summary statistics (mean, 1st quartile, median and 3rd quartile) for both gross pay and total reward show that fulltime employees were better off in the public sector than in the private sector, and this result also held for breakdowns by sex.

It should be noted that this represents a simple comparison which does not take into account the different composition of the public and private sectors. In particular, jobs done in the private sector and the public sector may be quite dissimilar. Analysis of public and private sector pay differentials carried out by the Institute for Fiscal Studies (IFS) has found that 'pay levels in the public sector are probably not significantly out of line with those of similar workers in the private sector, once you take into account factors such as their age, education and qualifications ${ }^{3}$.

\section{Results - employees with pensions}

The total reward picture presented in the previous section is difficult to interpret because more than half of all employees in the private sector do not have a pension, compared with only one-tenth in the public sector. In some cases this lack of participation in the private sector may be due to lack of access to a pension scheme, while in others it may be due to employees choosing not to belong. This imbalance in pension participation rates between the public and private sectors makes it difficult to compare total reward (including employer pension contributions) in the two sectors. 
Table 2

Gross pay and total reward for those with pensions: summary statistics, ${ }^{1,2,3}$ April 2009

United Kingdom

f per week

\begin{tabular}{|c|c|c|c|c|c|c|c|c|}
\hline & \multicolumn{4}{|c|}{ Gross pay } & \multicolumn{4}{|c|}{ Total reward } \\
\hline & \multicolumn{3}{|c|}{ 1st } & \multirow{2}{*}{$\begin{array}{r}\text { 3rd } \\
\text { quartile }\end{array}$} & \multicolumn{3}{|c|}{ 1st } & \multirow{2}{*}{$\begin{array}{r}3 \mathrm{rd} \\
\text { quartile }\end{array}$} \\
\hline & Mean & quartile & Median & & Mean & quartile & Median & \\
\hline Total & 679 & 423 & 581 & 792 & 767 & 474 & 656 & 899 \\
\hline Men & 751 & 469 & 633 & 872 & 847 & 524 & 713 & 987 \\
\hline Women & 575 & 373 & 510 & 687 & 651 & 422 & 578 & 778 \\
\hline \multicolumn{9}{|c|}{ Private sector } \\
\hline Total & 735 & 441 & 604 & 865 & 814 & 477 & 666 & 962 \\
\hline Men & 786 & 479 & 649 & 920 & 873 & 522 & 712 & 1,025 \\
\hline Women & 598 & 358 & 494 & 708 & 658 & 387 & 542 & 779 \\
\hline \multicolumn{9}{|c|}{ Public sector } \\
\hline Total & 621 & 405 & 555 & 736 & 718 & 466 & 644 & 852 \\
\hline Men & 695 & 450 & 607 & 809 & 808 & 522 & 708 & 943 \\
\hline Women & 560 & 376 & 513 & 675 & 645 & 436 & 589 & 776 \\
\hline
\end{tabular}

Notes:

Source: $A S H E$

1 Results are for full-time employees on adult rates of pay whose earnings were not affected by absence.

2 Total reward is defined as gross pay plus employer pension contributions.

3 Excludes those without current pensions, defined as those without employer or employee contributions.

\section{Table 3}

\section{Total reward for those with contracted out pensions: summary} statistics, ${ }^{1,2,3,4}$ April 2009

United Kingdom

f per week

\begin{tabular}{lccrr}
\hline & Mean & 1st quartile & Median & 3rd quartile \\
\hline Total & 761 & 489 & 669 & 895 \\
Men & 849 & 548 & 732 & 986 \\
Women & 658 & 439 & 595 & 790 \\
Private sector & & & & \\
Total & 853 & 528 & 717 & 1,006 \\
Men & 906 & 572 & 760 & 1,059 \\
Women & 693 & 416 & 580 & 825 \\
Public sector & & & & 853 \\
Total & 719 & 468 & 645 & 943 \\
Men & 808 & 524 & 708 & 776 \\
Women & 645 & 437 & 589 & \\
\hline
\end{tabular}

\section{Notes:}

Source: $A S H E$

1 Results are for full-time employees on adult rates of pay whose earnings were not affected by absence.

2 Total reward is defined as gross pay plus employer pension contributions.

3 Excludes those without current pensions, defined as those without employer or employee contributions.

4 Excludes those who are not contracted out of the State Second Pension.

Therefore, in this section a comparison of total reward in the public and private sectors is made by looking at full-time employees with pension contributions (either from the employee or from the employer). Those without pensions are excluded, allowing comparisons on a like-for-like basis in terms of pension scheme participation.

Table 2 shows the summary statistics for gross pay and total reward for full-time employees who had a current pension in April 2009. Comparing total reward in the public and private sectors, the results show that, overall, full-time employees were better off in the private sector than in the public sector. Median total reward was $\mathfrak{E 6 6 6}$ per week in the private sector, compared with $£ 644$ per week in the public sector, while mean total reward was $£ 814$ per week in the private sector, compared with $£ 718$ per week in the public sector.

The picture differs for men and women. Men, particularly those at the upper end of the total reward distribution, were better off in the private sector - as shown by their advantage over counterparts in the public sector of 8 per cent at the mean and 9 per cent at the 3 rd quartile. Women, particularly at the lower end of the total reward distribution, were better off in the public sector - as shown by their advantage over counterparts in the private sector of 9 per cent at the median and 12 per cent at the 1st quartile.
Table 2 also shows gross pay for fulltime employees who had a current pension in April 2009. The picture for gross pay in this group is similar to that for total reward, suggesting that those who had a current pension in the private sector were also on higher wages or salaries than their counterparts without pensions. This is borne out by a comparison between private sector gross pay in Table 1 (all full-time employees) and Table 2 (those with pensions), those with pensions had median gross pay of $£ 604$ per week in April 2009 , compared with $£ 465$ for all full-time employees.

It could be argued that in order to produce a comparison of total reward in the public and private sectors on a fully like-forlike basis, the analysis should take account of differences between employees in terms of their pension schemes' contracting out status ${ }^{7}$. Most public sector schemes are contracted out (94 per cent of our sample of full-time employees with pension schemes in the public sector were in contracted out schemes). On the other hand, the majority of private sector schemes are not contracted out (only 36 per cent of our sample of fulltime employees with pension schemes in the private sector were in contracted out schemes).

Where schemes are not contracted out, employees receive part of their total reward in the form of employer National Insurance contributions towards a State Second Pension (S2P). However, the ASHE data on employer pension contributions presented in this article does not include these figures, so total reward is underestimated in Table 2 , especially in the private sector. Table 3 presents total reward results for members of contracted out schemes only, thus removing the cases where part of total reward is in the form of employer National Insurance contributions towards the S2P. This makes virtually no difference to the results for the public sector, but it increases the value of total reward in the private sector, thereby increasing the advantage of the private sector over the public sector. In Table 3 ,

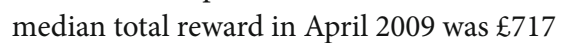
per week in the private sector, compared with $£ 645$ per week in the public sector, while mean total reward was $£ 853$ per week in the private sector, compared with $£ 719$ per week in the public sector.

Similarly, it could be argued that comparisons should be made for defined benefit (salary-based) schemes only because most public sector pension schemes are defined benefit, while schemes in the private sector are a mixture of defined 


\section{Figure 1}

\section{Employer pension contributions for those with pensions, ${ }^{1,2}$ April 2009}

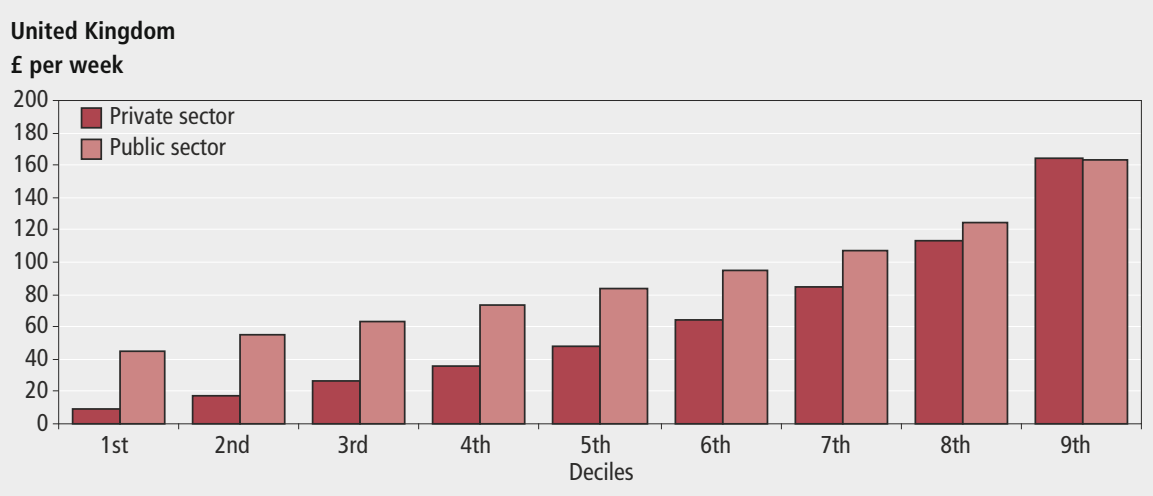

Notes:

Source: $A S H E$

1 Results are for full-time employees on adult rates of pay whose earnings were not affected by absence.

2 Excludes those without current pensions, defined as those without employer or employee contributions.

\section{Figure 2}

\section{Employer pension contributions for all full-time employees, ${ }^{1,2}$}

\section{April 2009}

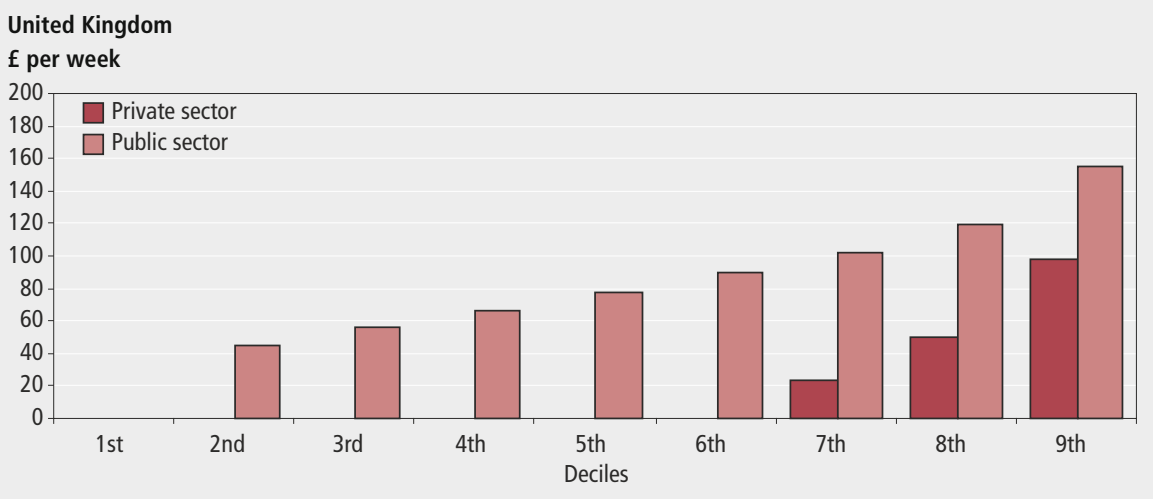

\section{Notes:}

Source: $A S H E$

1 Results are for full-time employees on adult rates of pay whose earnings were not affected by absence.

2 Includes those without current pensions (zero pension contributions)

\section{Figure 3}

Total reward for those with pensions, ${ }^{1,2,3}$ April 2009

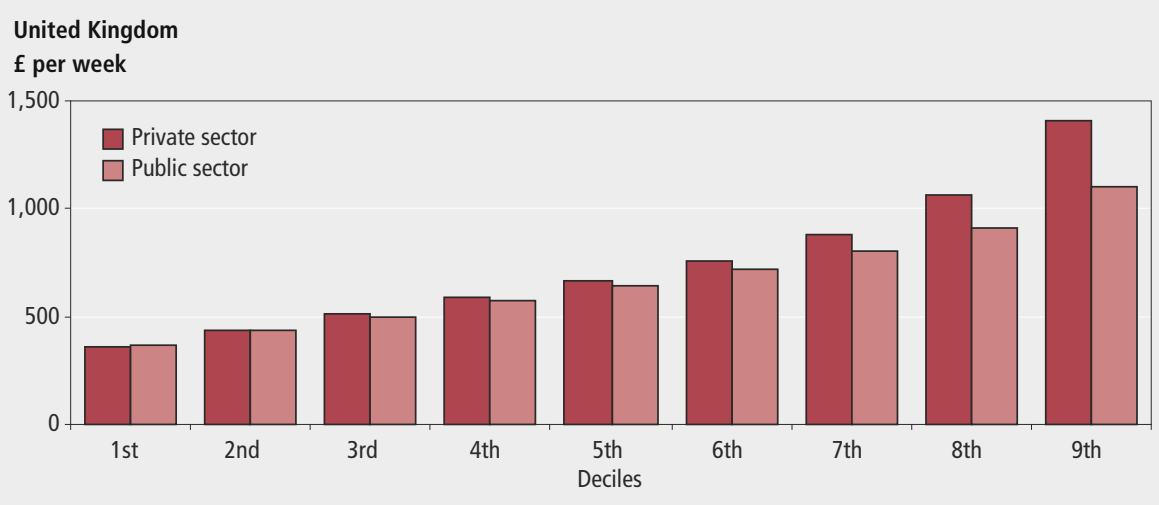

\section{Notes:}

Source: $A S H E$

1 Results are for full-time employees on adult rates of pay whose earnings were not affected by absence.

2 Total reward is defined as gross pay plus employer pension contributions.

3 Excludes those without current pensions, defined as those without employer or employee contributions. benefit and defined contribution (money purchase) schemes. This comparison is not presented here but, as employer pension contributions in defined benefit schemes are, on average, higher than employer contributions in defined contribution schemes $^{8}$, a comparison excluding defined contribution schemes would again increase the advantage of private sector employees over public sector employees.

\section{Distributional analysis}

This section presents distributions of employer pension contributions and total reward. The charts show distributions based on decile points. The analysis divides the data, sorted in ascending order, into ten equal parts so that each part contains 10 per cent (one-tenth) of the distribution - from the lowest values to the highest values. The charts presented here do not include the top (10th) decile point, because in some cases (at the top end of the earnings distribution), employer pension contributions and total reward may be artificially inflated, as discussed earlier in the article.

First, the analysis looks at employer pension contributions. Figure 1 shows, for full-time employees with current pensions, a comparison between the decile distributions for public and private sector employees. It shows that at all points except for the 9th decile point, employer pension contributions were higher in the public sector than in the private sector in April 2009. This gap is particularly marked at the lower end of the distribution.

Figure 2, which shows the distribution for all full-time employees, including those without current pensions, is included for comparison. This shows a far greater difference between the sectors because of the inclusion of full-time employees - mainly in the private sector - who did not belong to employer pension schemes in April 2009 (zero employer pension contributions).

Figure 3 shows the distribution of total reward for full-time employees with current pensions in the public and private sectors in April 2009. It shows that at all points except for the 1st decile point, total reward was higher for employees in the private sector than in the public sector. This was particularly the case at the upper end of the earnings distribution: total reward was 10 per cent higher in the private sector than in the public sector at the 7th decile point, rising to 28 per cent higher at the 9th decile point. The advantage of private sector employees with pensions over their public sector counterparts is not, for the 


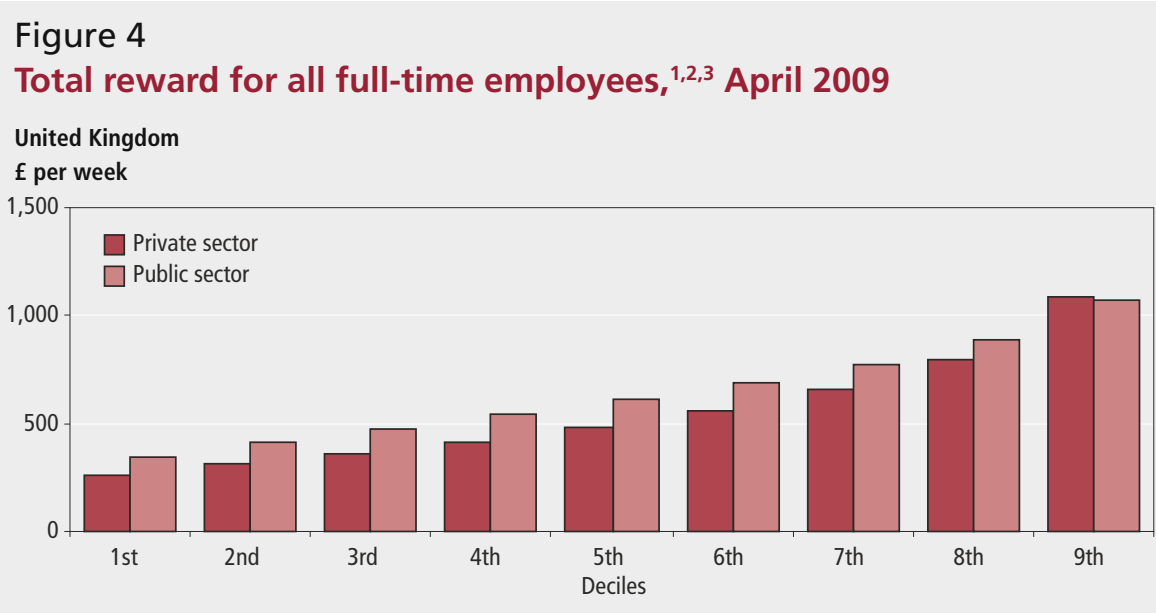

Notes:

Source: ASHE

1 Results are for full-time employees on adult rates of pay whose earnings were not affected by absence.

2 Total reward is defined as gross pay plus employer pension contributions.

3 Includes those without current pensions (zero pension contributions).

Figure 5

Median total reward for those with pensions by age, ${ }^{1,2,3}$ April 2009

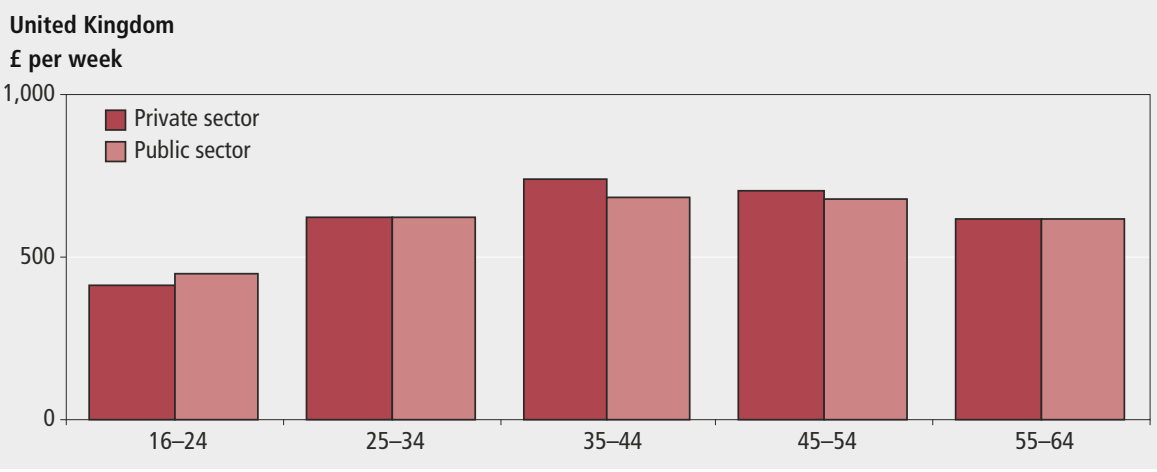

Notes:

Source: ASHE

1 Results are for full-time employees on adult rates of pay whose earnings were not affected by absence.

2 Total reward is defined as gross pay plus employer pension contributions.

3 Excludes those without current pensions, defined as those without employer or employee contributions.

most part, due to higher employer pension contributions (as demonstrated by Figure

1), but due to higher levels of gross pay.

Thus, in general, full-time private sector employees with pensions have higher absolute levels of total reward than those in the public sector and receive a greater proportion of this total reward in the form of pay while they are working. By contrast, full-time public sector employees with pensions have lower absolute levels of total reward, and a higher proportion is in the form of employer contributions to pensions which they will receive in retirement.

Figure 4 shows, for comparison, the distribution of total reward for all fulltime employees in the public and private sectors in April 2009. It includes fulltime employees, mainly in the private sector, who did not belong to employer pension schemes in April 2009. From this perspective, public sector employees have the advantage over their private sector counterparts (until the 9th decile).

\section{Breakdowns by key characteristics}

This section explores total reward for fulltime employees with pensions in relation to two of their key characteristics: age and occupation. It also examines two important characteristics of the organisations they work for: size of the organisation and industrial sector. In future articles, it is planned to provide breakdowns for men and women and also to present results for part-time employees.

Figure 5 shows median total reward by age of employee for people of working age. The overall trends are similar for the public and private sectors, with median total reward at its lowest for those in the 16 to 24 age group, rising to its highest in the 35 to 44 age group and then falling somewhat for employees who are closer to retirement. It should be noted that the trends do not necessarily reflect the life cycles of individual employees; they may be the result of cohort effects, with younger employees experiencing different working environments from older employees.

Figure 5 also shows that in April 2009 the median total reward of public sector employees in the 16 to 24 age group was higher than that of employees in the private sector ( $£ 451$ per week and $£ 413$ per week respectively). By contrast, median total reward of employees aged 35 to 44 and 45 to 54 in the private sector was higher than that of their counterparts in the public sector. The largest difference can be seen for employees aged 35 to 44 , where those in the private sector received $£ 738$ per week and those in the public sector received $£ 684$ per week in April 2009.

An examination of median total reward by occupation (see Figure 6) shows that 'management and senior officials' had the highest values in both the public and private sectors, with those in the private sector receiving $£ 958$ per week and those in the public sector receiving $£ 927$ in April 2009. For the majority of occupations, full-time employees in the private sector were better remunerated than their counterparts in the public sector, with the biggest gaps being in 'skilled trades' and 'personal services', where the difference between median total reward in the two sectors was $£ 77$ and $£ 78$ per week respectively. However, there were also some occupations where full-time employees in the public sector were better remunerated than their counterparts in the private sector, in particular 'sales and customer services' where employees in the public sector received median total reward of $£ 93$ per week more than in the private sector.

Figure 7 shows total reward by the size of the company or other organisation in which the employee works. People working full-time in small organisations in the public sector received higher total reward in April 2009 than in similar-sized companies in the private sector. This is most apparent in companies with 99 employees or fewer, where employees in the public sector received $£ 668$ per week, while employees in the private sector received $£ 601$ per week.

However, the pattern is reversed for organisations with 500 employees or more. In companies of this size or over in the private sector, employees had higher total reward than in a similar-sized organisations in the public sector. In April 2009, the gap was widest for organisations with 10,000 to 


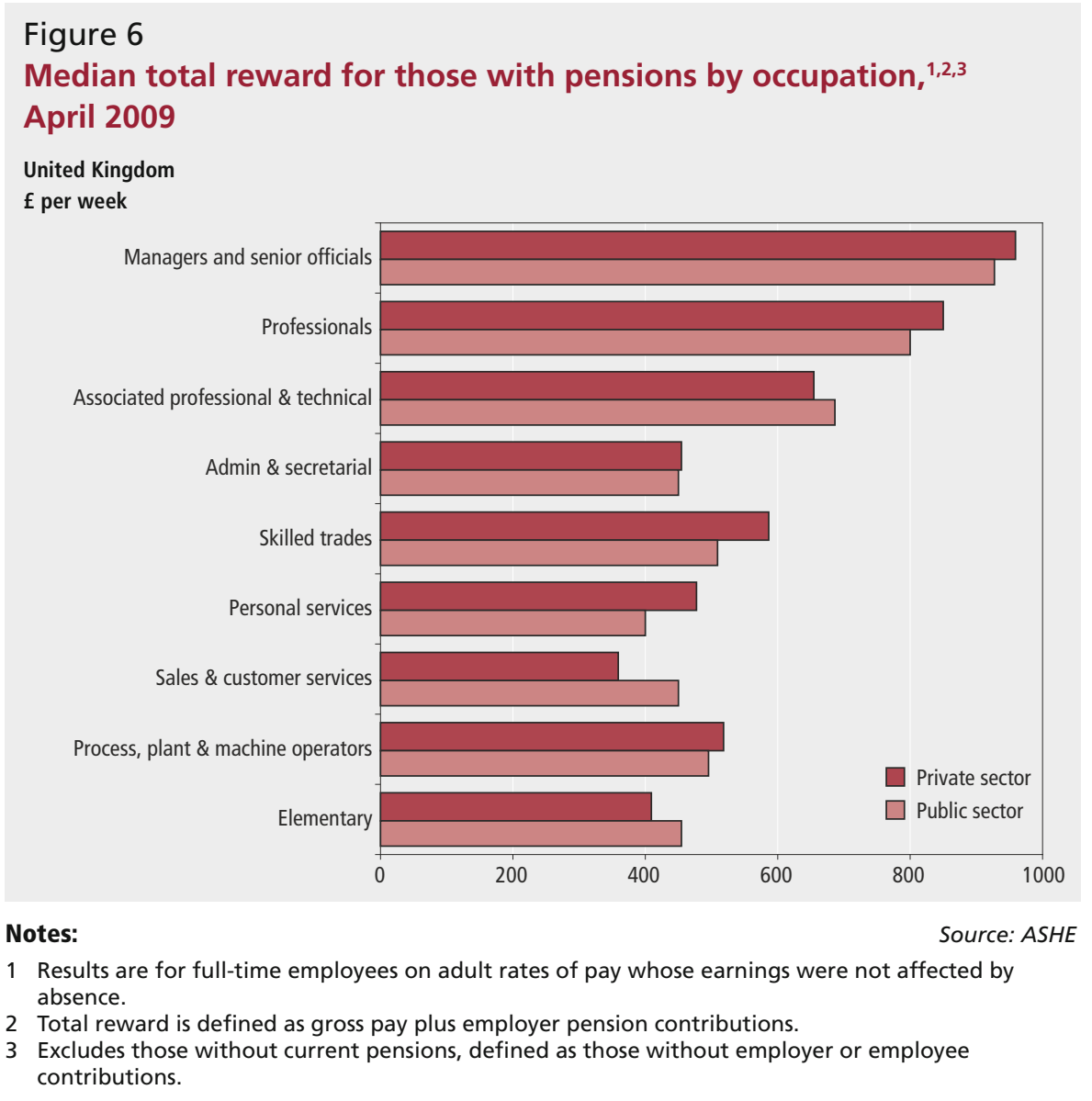

Figure 7

Median total reward for those with pensions by size of organisation, ${ }^{1,2,3}$ April 2009

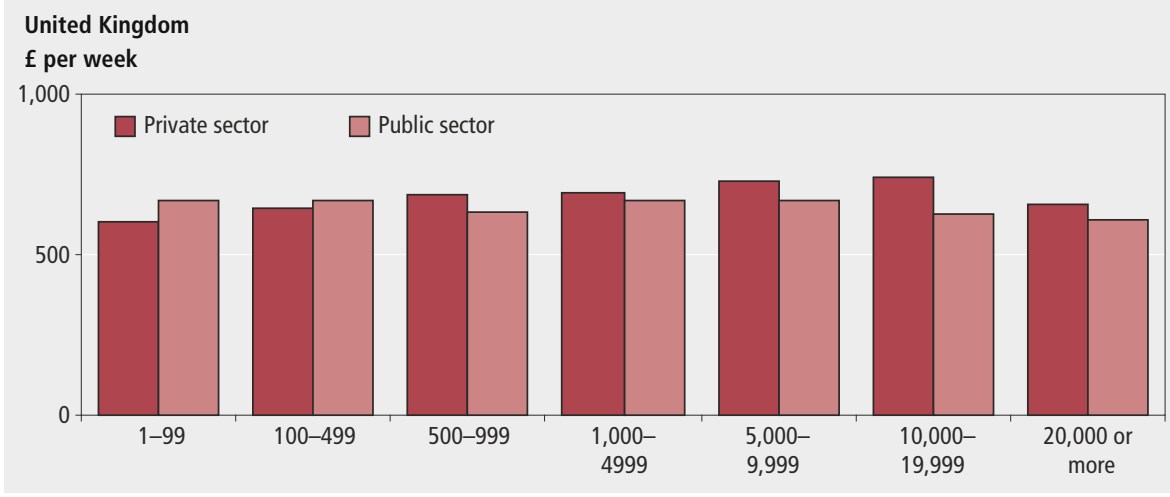

Notes:

Source: $A S H E$

1 Results are for full-time employees on adult rates of pay whose earnings were not affected by absence.

2 Total reward is defined as gross pay plus employer pension contributions.

3 Excludes those without current pensions, defined as those without employer or employee contributions.

19,000 employees, where the difference in median total reward was $\mathfrak{£} 118$ per week.

Figure 8 examines median total reward of full-time employees according to the industry sectors they work in. The sectors shown are not a full list: industry sectors are not shown if they do not exist in the public sector - and therefore cannot offer a comparison with the private sector - or if sample sizes are too small to present reliable estimates.
The employees who received the highest total reward in both public and private sectors in April 2009 were employed in the information and communications industry, where those in the public sector received $£ 48$ per week more than in the private sector. The industry with the largest difference in total reward was the manufacturing industry, where median total reward in the public sector was $£ 216$ per week higher than in the private sector. In 'human health and social work', employees in the public sector also did better, with a median total reward of $£ 123$ per week more than those in the private sector. On the other hand, employees in the private sector were better remunerated than their public sector counterparts in the transportation and storage, financial and insurance, real estate and professional, scientific and technical industries, and in education.

Caution is required when interpreting comparisons between industry sectors because the sub-sectors involved and the type of jobs done are often different in the public and private sectors. For instance manufacturing in the private sector is diverse, while in the public sector it is specialised, mainly involving defencerelated industries. Another example is 'human health and social work'. It has been noted that in April 2009 median total reward for full-time public sector employees in human health and social work was $£ 123$ per week more than for those in the private sector. Some of this is because, for particular occupational groups, the public sector provides a higher total reward: the biggest gap is that 'doctors and other health professionals' had median total reward of $£ 1,308$ per week in the public sector but $£ 1,091$ per week in the private sector ( $£ 216$ higher). Where other occupational groups can be compared, the gaps were smaller - for instance $£ 34$ for nurses and other health associate professionals (see Figure 9).

However, the occupational mix is different between the public and private sectors. In April 2009, 14 per cent of the public sector staff in human health and social work were 'doctors and other health professionals', but only 6 per cent of the private sector staff were in this highly paid group. At the lower paid end of the range, 8 per cent of private sector staff in this industry sector were 'care assistants or home carers', compared with only 2 per cent of public sector staff. These variations in the composition of the workforce are important in explaining the overall difference between the public and private sectors.

\section{Conclusion}

Total reward for full-time employees is higher in the public sector than the private sector if employees who do not belong to employer pension schemes (with zero pension contributions) are included in the analysis. This is because those without pensions (57 per cent of full-time employees in the private sector compared with 10 per cent in the public sector) reduce 


\section{Figure 8 \\ Median total reward for those with pensions by selected industry sector, ${ }^{1,2,3,4}$ April 2009 \\ United Kingdom \\ f per week}

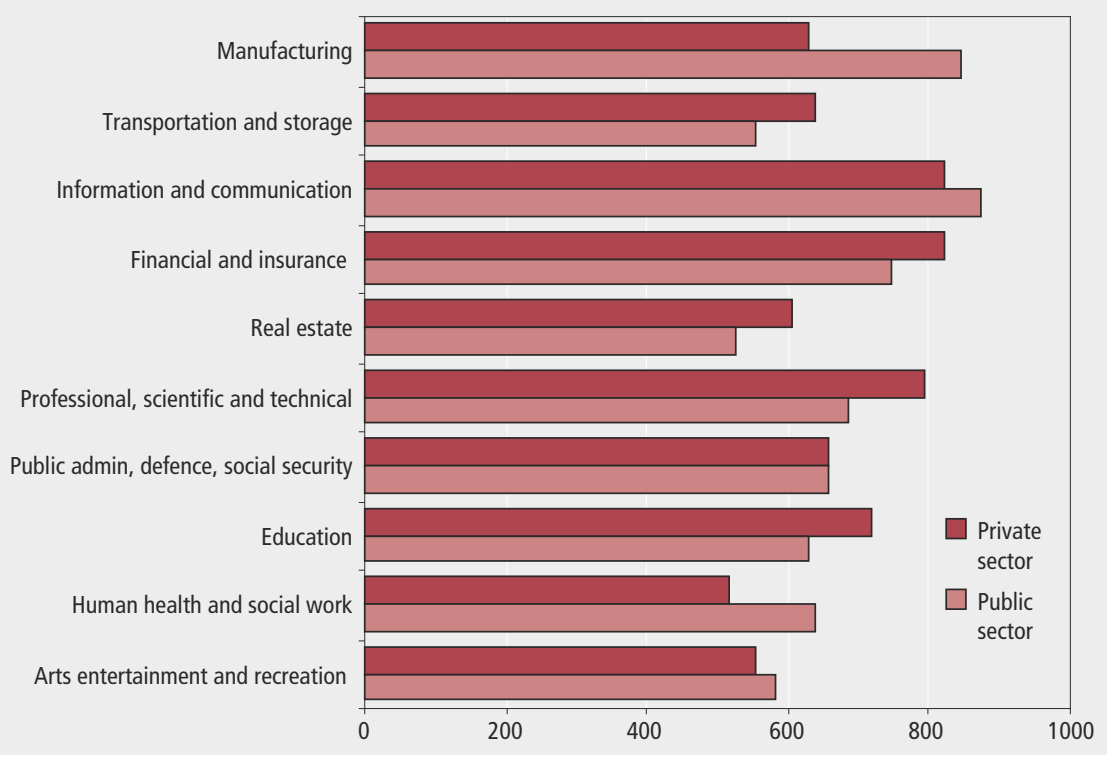

Notes:

Source: $A S H E$

1 Results are for full-time employees on adult rates of pay whose earnings were not affected by absence.

2 Total reward is defined as gross pay plus employer pension contributions.

3 Excludes those without current pensions, defined as those without employer or employee contributions.

4 Industries are grouped according to the Standard Industrial Classification (SIC) 2007.

\section{Figure 9}

Median total reward for those with pensions: selected occupations in the human health and social work sector, 1,2,3 April 2009

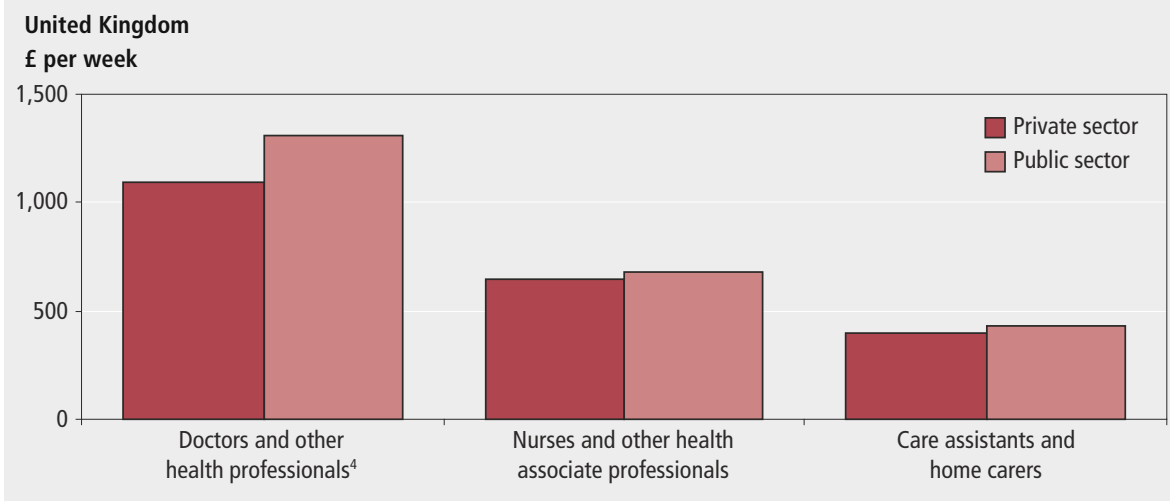

\section{Notes:}

Source: $A S H E$

1 Results are for full-time employees on adult rates of pay whose earnings were not affected by absence.

2 Total reward is defined as gross pay plus employer pension contributions.

3 Excludes those without current pensions, defined as those without employer or employee contributions.

4 Readers should treat the result for 'doctors and other health professionals' in the private sector with caution as the sample size is small.

the private sector average figures more than those of the public sector.

A comparison of total reward on a like-for-like basis, comparing full-time employees with pensions in both sectors, produces a different result. On this basis, total reward is higher in the private sector than the public sector - even more so after excluding employees in schemes that are not contracted out of the State Second Pension. Distributional analysis shows that the gap between private and public sector employees is particularly marked at the top end of the distribution.
There are a few exceptions to the general rule that, for those with pensions, the private sector provides better overall remuneration. The main exception is those on low pay, especially women, who have higher levels of total reward in the public sector than in the private sector. Young employees (aged 16 to 24 ), those in some occupations such as sales and customer services, and people employed in small organisations and certain industrial sectors were also found to be better rewarded in the public sector than in the private sector. However in general, for full-time employees who are members of employer pension schemes, total reward is greatest in the private sector.

\section{Notes}

1. ASHE results and methodology are available at:

www.statistics.gov.uk/StatBase/Product. asp?vlnk $=15236$

2. See the Commission's terms of reference at: www.hm-treasury.gov.uk/indreview_ johnhutton_pensions.htm

3. Pension Trends is available at: www.statistics.gov.uk/pensiontrends/

4. See Jenkins J and Leaker D (2009) 'The labour market across the UK in the current recession' (November 2009) at: www.statistics.gov.uk/cci/article. asp?ID=2310 and the Average Weekly Earnings index at: www.statistics.gov. uk/downloads/theme_labour/AWE_ Supplementary_tables.xls

5. For further analysis of pension scheme participation in the UK, including differences between sectors, see Pension Trends Chapters 6 and 7 at: www.statistics.gov.uk/pensiontrends/

6. Antoine Bozio and Paul Johnson 'Public sector pay and pensions' in Robert Chote, Carl Emmerson and Jonathan Shaw (eds) The IFS Green Budget: February 2010, available at: www.ifs.org.uk/publications/4732

7. If a scheme is 'contracted out' of the State Second Pension (S2P) it will have lower employer and employee National Insurance contributions than if it is 'not contracted out' and continues to pay National Insurance contributions at standard rates.

8. See Pension Trends Chapter 8 at: www.statistics.gov.uk/pensiontrends/

\section{CONTACT}

凶 elmr@ons.gsi.gov.uk 